\title{
CORRECTION
}

\section{Correction to: Biological mesh extrusion months after laparoscopic ventral rectopexy}

\author{
P. Sileri ${ }^{1} \cdot$ M. Shalaby ${ }^{1,2}$
}

Published online: 15 October 2018

(c) Springer Nature Switzerland AG 2018

Correction to: Tech Coloproctol (2017) 21:323-324

https://doi.org/10.1007/s10151-017-1610-3

Unfortunately, the 2nd affiliation of Dr. M. Shalaby has been missed out in the original publication. The complete $2 \mathrm{nd}$ affiliation of the same is given below.

Department of General Surgery, Mansoura University, Mansoura, Egypt.

The original article can be found online at https://doi.org/10.1007/ s10151-017-1610-3.

P. Sileri

piersileri@yahoo.com

1 University of Rome Tor Vergata, Rome, Italy

2 Department of General Surgery, Mansoura University, Mansoura, Egypt 